\title{
Prevalence and Clinical Anatomic Characteristics of Cryptorchidism in Schools in the City of Conakry
}

\author{
Thierno Mamadou Oury Diallo1,2, Mamadou Diawo Bah',2, Daouda Kante ${ }^{1,2}$, \\ Mamadou II. Barry ${ }^{1,2}$, Demba Cisse ${ }^{1,2}$, Mamadou Bissiriou Bah ${ }^{1,2}$, Lahoumbo Ricardo Gnammi1,2, \\ Ibrahima Bah",2, Abdoulaye Bobo Diallo1,2, Oumar Raphiou Bah ${ }^{1,2}$
}

${ }^{1}$ Urology Andrology Department of Ignace-Deen Hospital, HUC of Conakry, Conakry, Guinea

${ }^{2}$ Gamal Abdel Nasser University, Conakry, Guinea

Email: bobodiallo@hotmail.com

How to cite this paper: Diallo, T.M.O., Bah, M.D., Kante, D., Barry, M.II., Cisse, D., Bah, M.B., Gnammi, L.R., Bah, I., Diallo, A.B. and Bah, O.R. (2020) Prevalence and Clinical Anatomic Characteristics of Cryptorchidism in Schools in the City of Conakry. Open Journal of Urology, 10, 293-299.

https://doi.org/10.4236/oju.2020.1012034

Received: August 22, 2020

Accepted: December 25, 2020

Published: December 28, 2020

Copyright $\odot 2020$ by author(s) and Scientific Research Publishing Inc. This work is licensed under the Creative Commons Attribution International License (CC BY 4.0).

http://creativecommons.org/licenses/by/4.0/

\section{(c) (i) Open Access}

\begin{abstract}
Objective: To report the prevalence, anatomic and clinical characteristics of cryptorchidism in schools in the city of Conakry. Material and Methods: We carried out a 6-month cross-sectional study which took place in 32 public and private general education establishments in the city of Conakry. Each student boy was interviewed and examined; some information was collected from parents over the phone. Results: The prevalence of cryptorchidism was 3.6\%. It was higher among children of mothers who were not in school, and among those who attended public institutions. The average age of students with cryptorchidism was $9.84 \pm 2.33$ years, with extremes of 4 and 17 years. $85 \%$ of these pupils were born in a care structure (CHU, municipal hospital, health center). Cryptorchidism sat on the right in 64 cases (37.4\%), on the left in 44 cases (25.7\%), it was bilateral in 63 cases (36.9\%). The testicle was palpable at the inguinal level in 77 cases or $45 \%$ of the cases. Conclusion: Many school children have cryptorchidism at advanced ages, thus exposing them to the risk of complications (infertility and malignant degeneration of the testicle). Raising awareness among the various players could reverse this trend.
\end{abstract}

\section{Keywords \\ Cryptorchidism, Prevalence, Pupils, School}

\section{Introduction}

Cryptorchidism is the most common genital defect in boys [1]. It indicates the presence of a testicle, spontaneously and permanently, outside the scrotum at 
any point of its normal migration path [2].

It is an obvious pathology, clinically detectable in front of the vacuity of one or both purses. Often neglected by children and their parents in our country due to a lack of information or difficulties accessing healthcare facilities, cryptorchidism can lead to sometimes dramatic consequences when it is not taken care of early. Its main complications are the risk of infertility, malignant degeneration and torsion of the testicle [1] [3].

It is to minimize this risk that most teams currently recommend lowering an undescended testicle at the age of 1 year [4] [5] [6], from which testicular migration is no longer possible spontaneously [1].

In many countries, cryptorchidism is treated at late ages, due to diagnostic delay, as evidenced by school prevalence surveys.

In Turkey in 1996, Simsek [7] noted a prevalence of $1.43 \%$ of cryptorchidism in schools.

In Nigeria in 2001 in Anambra state, Okeke [8] found a 0.82\% prevalence of cryptorchidism in elementary school boys.

In our daily practice, it is not uncommon to find this anomaly in adolescents and adults. So we conducted this study in order to report the prevalence and anatomo-clinical characteristics of cryptorchidism in schools in the city of Conakry. This will ultimately enable us to sensitize populations and practitioners on the importance of early treatment.

\section{Material and Methods}

This was a descriptive cross-sectional study that took place in two municipalities (Matam and Dixinn) of Conakry town, capital of the Republic of Guinea. At the time of the study, the municipality of Dixinn had 134 primary and secondary schools, public and private, and that of Matam 186 schools, making a total of 320 schools. The total number of pupils enrolled in the two municipalities was 93,019 , of which 47,426 were boys. We randomly chose $10 \%$ of the total school population in each municipality. For each school, we randomly selected $10 \%$ of the total student population. This allowed us to obtain a sample of $4750 \mathrm{stu}-$ dents.

The study was sponsored by the national school health service, which issued us a mission order with which we went to the various schools. We carried out a large information of the teachers, the pupils and their parents on the objectives and the progress of the study.

Only boy students whose parents freely agreed to participate in the study were included in the study. It should be noted that the study took place during the Ebola virus crisis, causing reluctance in some parents of students.

The students were examined by two doctors enrolled in the Urology Specialist Studies Diploma in a room equipped with an examination table for the occasion. Palpation of the scrotum and groin was performed on confident children who were placed in the supine position. The appearance of the scrotum was noted. 
When the testicle was absent from the scrotum, it was carefully searched for by inguinal and iliac fossa palpation. If the testicle was palpated in the groin, it was moved by gentle traction towards the bursa to eliminate an oscillating testicle. Thus, the diagnosis of cryptorchidism was made when the testis was not found and when the testicle palpated in the groin could not be drawn into the bursa. A general exam had completed the examination of the bursa and penis, looking for an associated abnormality.

The variables collected for each child were age, educational level of the child, place of birth, educational level of the mother, profession of the father and for pupils with cryptorchidism, the side of the anomaly, the topography of the undescended testicle, and associated anomalies were noted.

It should be noted that some children were unable to provide certain data, including their place of birth, their mother's level of education and whether they were informed of their illness. In these cases, these information were taken from the parents on the telephone.

The data were analyzed on Epi Info in its 7.1.3.3 version.

\section{Results}

We examined a total of 4750 students, of which 171 had cryptorchidism, a prevalence of $3.6 \%$. This prevalence was variable according to certain variables (Table 1).

The mean age of students with cryptorchidism was $9.84 \pm 2.33$ years, with extremes of 4 and 17 years. The most represented age group was 6 - 10 years old (Table 2).

Regarding the place of birth of students with cryptorchidism, the CHU was the most reported with $42.6 \%$ of cases (Figure 1 ).

We noted that $12 \%$ of the parents were already informed of the anomaly and claimed to have consulted a specialist but finally withdrew due to the high cost of care.

According to the side, the anomaly was located on the right in 64 cases (37.4\%), on the left in 44 cases (25.7\%), it was bilateral in 63 cases (36.9\%).

Table 1. Prevalence of cryptorchidism according to certain variables.

\begin{tabular}{ccccc}
\hline \multicolumn{2}{c}{ Variables } & $\begin{array}{c}\text { Number of children } \\
\text { with cryptorchidism }\end{array}$ & Total & Prevalence (\%) \\
\hline $\begin{array}{c}\text { Mother } \\
\text { educational } \\
\text { level }\end{array}$ & Un schooled & 118 & 2520 & 4.68 \\
$\begin{array}{c}\text { Type of school } \\
\text { frequented }\end{array}$ & Pre-university & 49 & 1968 & 2.88 \\
$\begin{array}{c}\text { Child educational } \\
\text { level. }\end{array}$ & Private & 4 & 532 & 0.75 \\
& Primary & 149 & 2977 & 5 \\
\hline & Secondary & 157 & 1773 & 1.24 \\
& & 14 & 4177 & 3.75 \\
\hline
\end{tabular}


Table 2. Distribution of students with cryptorchidism according to age groups.

\begin{tabular}{ccc}
\hline Age (Revolved years) & Effectif & Percentage \\
\hline $1-5$ & 4 & 2.3 \\
$6-10$ & 143 & 83.6 \\
$11-15$ & 21 & 12.3 \\
$\geq 16$ & 3 & 1.8 \\
Total & 171 & 100 \\
\hline
\end{tabular}

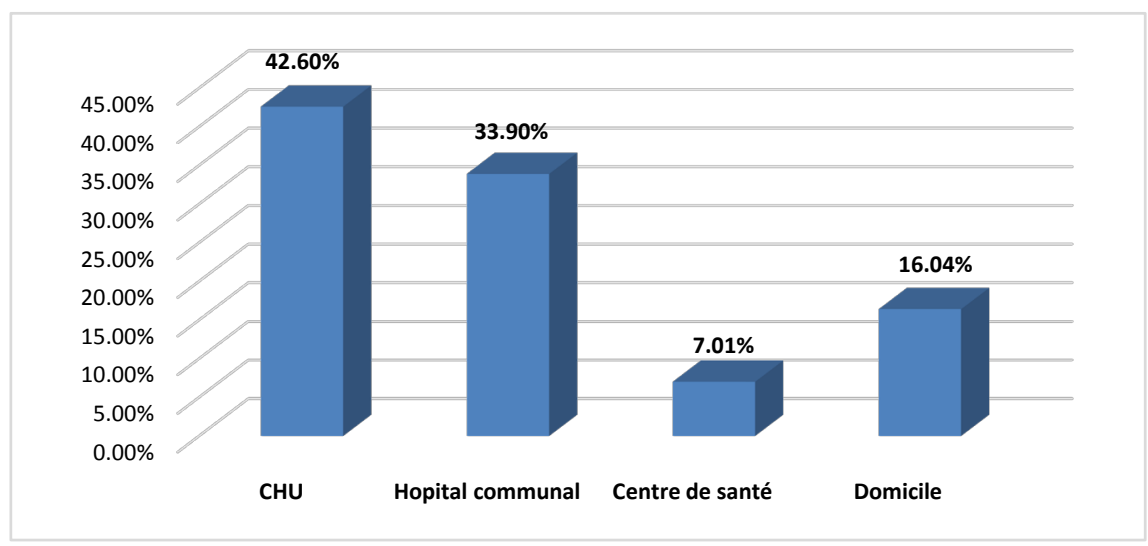

Figure 1. Distribution according to the place of birth and children with cryptorchidism.

According to the topography, the testicle was palpable at the inguinal level in 77 cases or $45 \%$ : at the root of the purse in 12 cases, i.e. $6.4 \%$.

Other abnormalities were associated with cryptorchidism in some students. These were 12 cases of contralateral hydrocele, 7 cases of varicocele, 3 cases of medium penile hypospadias, 2 cases of balanic hypospadias and 4 cases of phimosis.

Of the 171 students with cryptorchidism, only 29 cases (16.95\%) were able to be managed in our service.

\section{Discussion}

The prevalence of cryptorchidism in school-aged children varies widely in the literature. One of the highest rates was found in Denmark with a prevalence of $7 \%$ in boys aged 6 to 16 [9]. It was 2.1\% in boys aged 6 to 12 years in a Jordanian study [10], while it was $1.41 \%$ in a Senegalese study reported by Gueye [11]. In our survey, we found a prevalence of $3.6 \%$. However, we did not consider the existence of acquired cryptorchidism, which could overestimate the prevalence of true cryptorchidism in the study. Indeed, at school age, a testicle normally descended during the first year of life can ascend and secondarily fix in a high position, producing acquired cryptorchidism [1]. Hack noted a prevalence of acquired cryptorchidism of $2.2 \%$ in boys aged 6 to 13 [12].

The average age of students with testicular dystopia in our study was $9.84 \pm$ 2.33 years with extremes of 4 and 17 years. The age of discovery advanced in our 
work, as in many African series [2] [13] [14], exposes these children to a risk of infertility, and degeneration of the testicle.

The low socio-economic level has been identified as a major risk factor for diagnostic delay [15], which is probably due to the parent's lack of information and their difficulties in accessing medical structures.

Even if we did not study the standard of living in this study, it still appears that the prevalence of cryptorchidism is higher in the group of children whose mothers did not attend schools and in those who are attending public educational institutions.

It should also be noted that in $12 \%$ of the cases, the parents were already informed of the anomaly but could not cope with the high cost of care in health facilities, where they do not benefit from any social assistance.

In addition, $85 \%$ of children with cryptorchidism were born in a health facility, half of them in a CHU.

This should challenge health providers (midwives, obstetricians, pediatricians) as long as the systematic examination of the newborn in the delivery room should make it possible to detect the anomaly which is easy to diagnose [2] in the case of vacuity one or both testicle purse. Once the diagnosis has been made, children should be systematically referred to specialists for optimal management.

We notified $63.1 \%$ of unilateral cryptorchidism, with a predominance on the right side which represented $37.4 \%$ of the cases; these results corroborate the data in the literature [1] [2] [11].

The bilateral nature of the anomaly as it is the case in $36.4 \%$ of cases in our work increases the risk of infertility [16]. Lee et al. [16] reported a 59\% male infertility rate in patients who underwent testicular lowering during childhood for bilateral cryptorchidism.

Bilaterality may be a factor in the early diagnosis of the anomaly for some authors [17].

In about $80 \%$ of cases, the cryptorchid testis is palpable [1]. The $51 \%$ rate of palpable testes in our survey is probably underestimated. In fact, the conditions of the investigation make it difficult to obtain good muscle relaxation in the child during the examination [11]. It should also be noted that on a single examination it is difficult to determine whether a palpable testicle at the root of the bursa (12 cases in our investigation) is cryptorchid or oscillating. If in doubt, the children should be seen again at other visits to determine the exact location of the testicle [15].

An associated penile anomaly would be a factor of consultation at a younger age [15]. In fact, the penis abnormality may be easier to detect by parents and may cause more concern for parents, who would request a quick consultation.

We noted 5 previous cases of balanic and penile hypospadias in our series. The fact that these hypospadias are minor could explain the possible lack of concern of the parents. 
Despite the awareness, we noted that only $16.95 \%$ of children with the anomaly could be cared for in our department or in the pediatric surgery department. This is certainly linked to the extreme poverty which considerably limits access to healthcare in our country.

The main limitation of this study is that acquired cryptorchidia was not considered. We did not have access to the student health record to know the position of the testicle at birth or in the first year of life.

\section{Conclusion}

Our work shows that many children have cryptorchidism at advanced ages. The prevalence was higher among students born in health structures, whose mothers were not solarized and who attended public school. To reverse this trend, it will probably require an effort to raise awareness at all levels, in particular midwives, pediatricians, but also education and public information. It is also necessary to create facilities for access to care for disadvantaged families.

\section{Conflicts of Interest}

The authors declare no conflicts of interest regarding the publication of this paper.

\section{References}

[1] Grapin-Dagorno, C., Bosset, P.-O., Boubnova, J. and Noche, M.-E. (2012) Cryptorchidism. Testicular Ectopy. EMC-Urologie, 5, 1-9.

[2] Fall, B., Fall, P.A., Ali, M., Diao, B., Sow Y., Kaboré, F.A., et al. (2009) Clinical, Biological and Therapeutic Aspects of Cryptorchidism Diagnosed in Adulthood: Analysis of a Series of 69 Cases. Andrology, 19, 168-172.

[3] Braga, L.H., Lorenzo, A.J. and Romao, R.L.P. (2017) Canadian Urological Association-Pediatric Urologists of Canada (CUA-PUC) Guideline for the Diagnosis, Management, and Followup of Cryptorchidism. Canadian Urological Association Journal, 11, E251-E260. https://doi.org/10.5489/cuaj.4585

[4] Snodgrass, W., Bush, N., Holzer, M. and Zhang, S. (2011) Current Referral Patterns and Means to Improve Accuracy in Diagnosis of Undescended Testis. Pediatrics, 127, e382-e388. https://doi.org/10.1542/peds.2010-1719

[5] Hadziselimovic, F. and Herzog, B. (2001) Importance of Early Postnatal Germ Cell Maturation for Fertility of Cryptorchid Males. Hormone Research, 55, 6-10. https://doi.org/10.1159/000049956

[6] Ritzen, E.M., Bergh, A., Bjerknes, R., Christiansen, P., Cortes, D., Haugen, S.E., et al. (2007) Nordic Consensus on Treatment of Undescended Testes. Acta Paediatrica, 96, 638-643.

[7] Simsek, F., Hayran, O., Tarcan, T., Ilker, Y. and Akdaş, A. (1995) Social and Medical Aspects of Undescended Testes in Turkey. European Urology, 28, 161-164. https://doi.org/10.1159/000475043

[8] Okeke, A.A. and Osegbe, D.N. (2001) Prevalence and Characteristics of Cryptorchidism in a Nigerian District. BJU International, 88, 941-945. https://doi.org/10.1046/j.1464-4096.2001.02414.x

[9] Blom, K. (1984) Undescended Testis and Time of Spontaneous Descent in 2516 
School Boys. Ugeskrift for Laeger, 146, 616-617

[10] Al-Abbadi, K. and Smadi, S.A. (2000) Genital Abnormalities and Groin Hernias in Elementary-School Children in Aqaba: An Epidemiological Study. East Mediterranean Health Journal, 6, 293-298.

[11] Gueye, S.M., Ba, M., Ndoye, A., Sylla, C., Fall, P.A. and Mensah, A. (1996) Cryptorchidism in Senegalese School-Age Children. Andrologie, 6, 287-291. https://doi.org/10.1007/BF03035283

[12] Hack, W.W., Sijstermans, K., Van Dijk, J., Van Der Voort-Doedens, L.M., De Kok, M.E. and Hobbelt-Stoker, M.J. (2007) Prevalence of Acquired Undescended Testis in 6-Year, 9-Year and 13-Year-Old Dutch School Boys. Archives of Disease in Childhood, 92, 17-20. http://dx.doi.org/10.1136/adc.2005.076208

[13] Ndour, O., Fall, M., Faye, A.L., Diouf, C., Ndoye, N.A., Ngom, G. and Ndoye, M. (2015) Epidemiological, Clinical and Therapeutic Aspects of Cryptorchidism in Children: Analysis of 123 Cases. African Journal of Urology, 21, 10-14. https://doi.org/10.1016/j.afju.2015.02.001

[14] Bouya, P.A., Odzébé, A.W.S., Avala, P.P., Ondongo Atipo, M., Koutaba, E. and Cardorelle Mbika, A.I. (2012) Management of Cryptorchidism at the Brazzaville Hospital and University Center. Andrologie, 22, 108-111.

[15] Bayne, A.P., Alonzo, D.G., Hsieh, M.H. and Roth, D.R. (2011) Impact of Anatomical and Socioeconomic Factors on Timing of Urological Consultation for Boys with Cryptorchidism. The Journal of Urology, 186, 1601-1605.

https://doi.org/10.1016/j.juro.2011.03.102

[16] Lee, P.A., O’Leary, L.A. and Songer, N.J. (1995) Paternity after Cryptorchidism: Lack of Correlation with Age of Orchidopexy. British Journal of Urology, 75, 704-711. https://doi.org/10.1111/j.1464-410X.1995.tb07375.x

[17] Zhao, T.-X., Liu, B., Wei, Y.-X., Wei, Y., Tang, X.-L., Shen, L.-J., et al. (2019) Clinical and Socioeconomic Factors Associated with Delayed Orchidopexy in Cryptorchid Boys in China: A Retrospective Study of 2423 Cases. Asian Journal of Andrology, 21, 304-308. https://doi.org/10.4103/aja.aja 10618 